\title{
RENAL CELL CARCINOMA IN PREGNANCY: A CASE REPORT
}

\author{
K. Saritha ${ }^{1}$, T. Shravya ${ }^{2}$, K. V. Sireesha ${ }^{3}$
}

\section{HOW TO CITE THIS ARTICLE:}

K. Saritha, T. Shravya, K. V. Sireesha. "Renal Cell Carcinoma in Pregnancy: A Case Report". Journal of Evolution of Medical and Dental Sciences 2015; Vol. 4, Issue 16, February 23; Page: 2818-2822,

DOI: $10.14260 /$ jemds/2015/403

\begin{abstract}
Renal cell carcinoma is uncommon during the reproductive phase of a woman. Diagnosis of renal cell carcinoma during pregnancy is usually delayed because it is asymptomatic in most cases and a complete ultrasound of abdomen is not a part of routine obstetric evaluation. Although radical nephrectomy is the definitive treatment of choice in renal cell carcinoma, the exact timing of surgery is controversial. Management of renal cell carcinoma during pregnancy requires multidisciplinary approach. We report a case of a second gravida presenting with a renal mass during the first trimester with a blighted ovum.
\end{abstract}

KEYWORDS: Kidney, pregnancy, Renal cell carcinoma.

INTRODUCTION: Malignancy during pregnancy is a rare event. It is estimated that less than $0.1 \%$ of pregnancies are complicated by any type of neoplasm and only $0.0013 \%$ (approx. 13 in 1,000,000 pregnancies) by urinary cancer. ${ }^{1}$ Diagnosis of renal cell carcinoma during pregnancy is delayed because it is asymptomatic in most cases and a complete ultrasound of abdomen is not a part of routine obstetric evaluation. We report a case of a second gravida presenting with a renal mass during the first trimester with a blighted ovum.

CASE REPORT: A 20 year old second gravida with one live child with one previous Caesarean section presented to the antenatal outpatient with history of 3 months amenorrhoea for confirmation of pregnancy. A pelvic examination revealed a uterus of 8 weeks size. She was sent for a USG, which showed gestational sac $26.6 \mathrm{~mm}$ with no sign of foetal heart and a blighted ovum. Liver, gall bladder, spleen and pancreas were normal. Right kidney showed a mixed semisolid mass 130x110 mm. There was no history of weight loss, haematuria, loss of appetite. There was no pallor, no icterus and temperature was normal. There was a palpable mass in the right lumbar region, which was firm in consistency and nontender. A diagnosis of G2P1L1 with previous LSCS with Missed abortion with right renal mass was made. All investigations including liver and renal function tests, clotting profile were normal. The pregnancy was terminated by medical abortion and check curettage was done. Repeat ultrasound scan showed an empty uterus and the patient was referred to the Urology department for evaluation and further management of the renal mass.

She was investigated by CT scan, which revealed a large well defined heterogeneous mass lesion measuring $13 \mathrm{~cm} \times 11 \mathrm{~cm} \times 9 \mathrm{~cm}$ in the posterolateral aspect of right kidney with marked enhancement in arterial phase and washout in delayed phase. The mass is seen causing splitting of residual right kidney (Claw sign position), features suggestive of malignant renal mass (Renal cell carcinoma.)

She underwent right radical nephrectomy. Gross specimen was weighing 700 gms. Cut section showed variegated appearance with no cortico-medullary differentiation. Histopathology revealed that tumour tissue was arranged in lobules, nests and cords separated by fibrous septae and rich 


\section{CASE REPORT}

capillary network. Tumour cells showed abundant clear cytoplasm, central ovoid vesicular nuclei, prominent nucleoli, mitosis (2-3/10 HPF), areas of necrosis and haemorrhage. Ureter was normal, adjacent renal parenchyma showed mild interstitial nephritis.-features suggestive of renal cell carcinoma, clear cell variant. She was discharged and asked to come for check-ups at six monthly intervals.

She subsequently conceived after 2 years and was attending local health center for antenatal check-ups. In view of her previous history of previous caesarean section and radical nephrectomy, she was referred to our hospital at term. All investigations including ultrasound were normal. She delivered a healthy male baby weighing $3 \mathrm{~kg}$ by caesarean section, her postoperative phase was uneventful.

DISCUSSION: Renal cell carcinoma is rare in women of childbearing age, but it is the most common renal neoplasm occurring in pregnancy accounting for half of all primary tumours.2. Other less common tumours include renal angiomyolipoma and oncocytoma which are benign. They have been noted to be more common in women of high parity but less in those who have been exposed to contraception. ${ }^{3}$

Walker and Knight reviewed the presentation of renal cell carcinoma during pregnancy and found that the commonest presenting symptoms of such tumour were a palpable mass (88\%), pain (50\%), haematuria (47\%), and hypertension (18\%).4 A subsequent review has suggested that there has been a change in the presentation of renal cell carcinoma in pregnant women, with diagnosis now more frequently made incidentally during ultrasound examination performed for other reasons, ${ }^{5}$ as happened in this case.

It has been proposed that pregnancy related hormonal changes may act as promoters for renal malignancy. For example, high oestrogen levels during pregnancy can promote malignant changes by stimulating renal cell proliferation. ${ }^{6}$ However, there has been no demonstrable immunodeficiency in pregnancy to antigens carried by tumour cells. ${ }^{7}$ Furthermore, in most cases, the biological behaviour of malignancy is not influenced by pregnancy. ${ }^{8}$

Diagnostic evaluation of the pregnant patient with possible renal carcinoma requires special consideration of non-invasive techniques and as little radiation exposure as possible to mother and foetus. ${ }^{9}$ Some authors have suggested that urine should be sent for cytological analysis, ${ }^{2}$ but unlike transitional cell carcinoma in renal cell carcinoma cytology is negative.

Ultrasonography is the safest method to diagnose a renal mass in pregnancy and has a relatively acceptable sensitivity (82\%). ${ }^{10}$ It can identify, differentiate between, and stage solid renal masses in most cases. It also avoids exposure of the foetus to radiation. Ultrasonography is less expensive and available in all places. MRI though more sensitive is expensive and not available in all hospitals. In nonpregnant patients IVP and abdominal CT are the modalities frequently employed in the evaluation of renal tumour, ${ }^{9}$ but in pregnancy there is no proven safe threshold dose of radiation exposure to the foetus. The use of Doppler ultrasound has been suggested as an alternative to IVP to assess the function of the contralateral kidney. ${ }^{11}$ In the present case abdominal CT was confirmatory and was done after evacuation of the pregnancy.

Since most small renal masses are asymptomatic there may be delay in diagnosis of renal cancer in pregnancy. Further assessment is not indicated largely because of insufficient safety data of radiation during pregnancy. ${ }^{12}$ Radiological assessment of extra pelvic organs is not part of routine 


\section{CASE REPORT}

antenatal screening. A full abdominal ultrasound during pregnancy will allow the early diagnosis of malignancies and diseases of other organs, as happened in this case. This slight modification of full abdominal ultrasound is fast, simple to perform, and safe for both foetus and mother. Some authors recommend that a total abdominal ultrasound be performed at least once in all pregnancies in addition to routine foetal ultrasonography. ${ }^{13}$

Maternal foetal prognosis in renal cell carcinoma largely depends on timely diagnosis and correct management at the appropriate time. Prognosis for the mother is directly related to the stage of malignancy. Surgical resection remains main stay of treatment. Timing of surgery for renal tumours during pregnancy is controversial. Timing of surgery is dictated by time of diagnosis, size and stage of tumour, probability of malignancy, general health of mother and probability of survival of foetus. Cure rate depends on the stage of malignancy. Most renal neoplasms are slow growing with an average volume doubling time of more than 500 days. ${ }^{14}$ Diagnosis of a suspicious malignant renal mass in the first trimester entails immediate surgery despite the small increased risk of miscarriage. ${ }^{15}$ In our case the decision for definite management was facilitated by the fact that the patient presented with blighted ovum.

Surgery during second trimester will need to balance the maternal and foetal risk of abortion and preterm labour with the risks of delaying surgery. Avoidance of disruption of the peritoneal cavity in the extra-peritoneal approach may theoretically be associated with less uterine irritation and in turn fewer obstetric complications, including preterm labour. ${ }^{2}$ This is especially critical in the management of small renal cancers due to increased risk of maternal - foetal adverse outcome before 32 weeks of gestation. ${ }^{16}$

If a renal mass is detected during the late stages of pregnancy it is reasonable to await foetal delivery before surgery. ${ }^{17}$ It is reasonably safe to observe small renal masses and a short delay in definite treatment in the third trimester, whereas for large tumours or tumours which exhibit very rapid growth nephrectomy should not be delayed. If the diagnosis of renal tumour is near term, nephrectomy should be postponed till post-delivery. However, some physicians recommend immediate nephrectomy irrespective of stage of pregnancy since the main priority is mother's health. ${ }^{18}$ In the presence of malignancy, maternal-foetal morbidity and mortality should be carefully considered with maternal health as top priority. ${ }^{19}$ The patient and her attenders need to be fully informed of all possible risks versus benefits of management options laid out through discussions in a multi-disciplinary conference (urologists, obstetricians, oncologists and neonatologists)

CONCLUSIONS: Renal cell carcinoma is an uncommon in pregnancy. Routine complete abdominal ultrasound evaluation during pregnancy enables early diagnosis of malignancy and also other diseases that might be asymptomatic. Definitive treatment is nephrectomy. Timing of surgery is controversial. Management of renal cell carcinoma during pregnancy requires multidisciplinary approach.

\section{REFERENCES:}

1. Smith LH, Danielsen B, Allen ME, Cress R. Cancer associated with obstetric delivery: Results of the linkage with the California cancer registry. Am J Obstet Gynecol 2003; 4: 1128-1135.

2. Gladman MA, MacDonald D, Webster JJ, Cook T, William G. Renal cell carcinoma in pregnancy J R Soc Med 2002; 95: 199- 201. 


\section{CASE REPORT}

3. Kabat GC, Navarro Silvera SA, Miller AB, Rohan TE. A cohort study of reproductive and hormonal factors and renal cell cancer risk in women. Br J Cancer 2007; 96: 845- 9.

4. Walker JL, Knight EL. Renal cell carcinoma in pregnancy Cancer 1986; 58: 2343 -7.

5. Smith DP, Goldman SM, Beggs DS, Lanigan PJ. Renal cell carcinoma in pregnancy: Report of three cases and review of literature Obstet Gynecol 1994; 83: 818-20.

6. Fynn J, Venyo AK. Renal cell carcinoma presenting as hypertension in pregnancy J Obstet Gynecol. 2004; 24: 821-822.

7. Donegan WL. Cancer and pregnancy CA cancer J Clin 1983; 33: 194-214.

8. Sutherland CM, Loutfi A, Mather FJ, Carter RD, Krementz ET. Effect of pregnancy upon malignant melanoma Surg Gynecol Obstet 1983; 157: 443-446.

9. Stoicescu M. Kidney tumor in pregnancy J Nephrol Ther 2013; 3: 138.

10. Warshauer DM, McCarthy SM, Street L, Bookbinder MJ, Glickman MG, Richter J et al. Detection of renal masses: Sensitivities and specificities of excretory urography/ linear tomography, US and CT. Radiology 1988; 169: 363-5.

11. Oduagbon OE, Orumuah AJ, Enoghama UE. Renal cell carcinoma in pregnancy. Afr J Med Health Sci 2013; 12: 49-51.

12. Tsivian M, Rampersaud EN, Jr., Del Pilar Laguna Pes M, Joniau S, Leveillee RJ, Shingleton WB et al. Small renal mass biopsy - how, what and when; report from an international consensus panel. BJU Int 2013. Doi: 10.1111/bju.12470

13. Kor Woi Tiang, Keng Lim Ng, Antonio Vega-Vega, Simon Wood Rapidly enlarging renal tumour during pregnancy: diagnostic and management dilemma journal of kidney cancer and VHL 2014;1(1): 12-16.

14. Boussios S, Pavlidis N. Renal cell carcinoma in pregnancy: a rare coexistence. Clin Transl Oncol 2014; 16: 122-127.

15. Wilcox AJ, Weinberg CR, O'Connor JF, Baird DD, Schlatterer JP, Canfield RE et al. Incidence of early loss of pregnancy. N Engl J Med. 1988; 319: 189-194.

16. Alouini S. Delay surgery for small renal cell cancers to week 32 of gestation. Nat Rev Urol 2010;7:doi:101038/nrurol2010 25-cl.

17. Bettez M, Carmel M, Temmar R, Core AM, Sauve N, Asselah J et al. Fatal fast-growing renal cell carcinoma during pregnancy. J Obstet Gynaecol Can 2011; 33: 258-261.

18. Gnessin E, Dekel Y, Baniel J. Renal cell carcinoma in pregnancy. Urology 2002; 60:1111.

19. Pentheroudakis G, Pavlidis N. Cancer and pregnancy: poena magna, not anymore Eur J Cancer 2006; 42:126-140. 


\section{CASE REPORT}

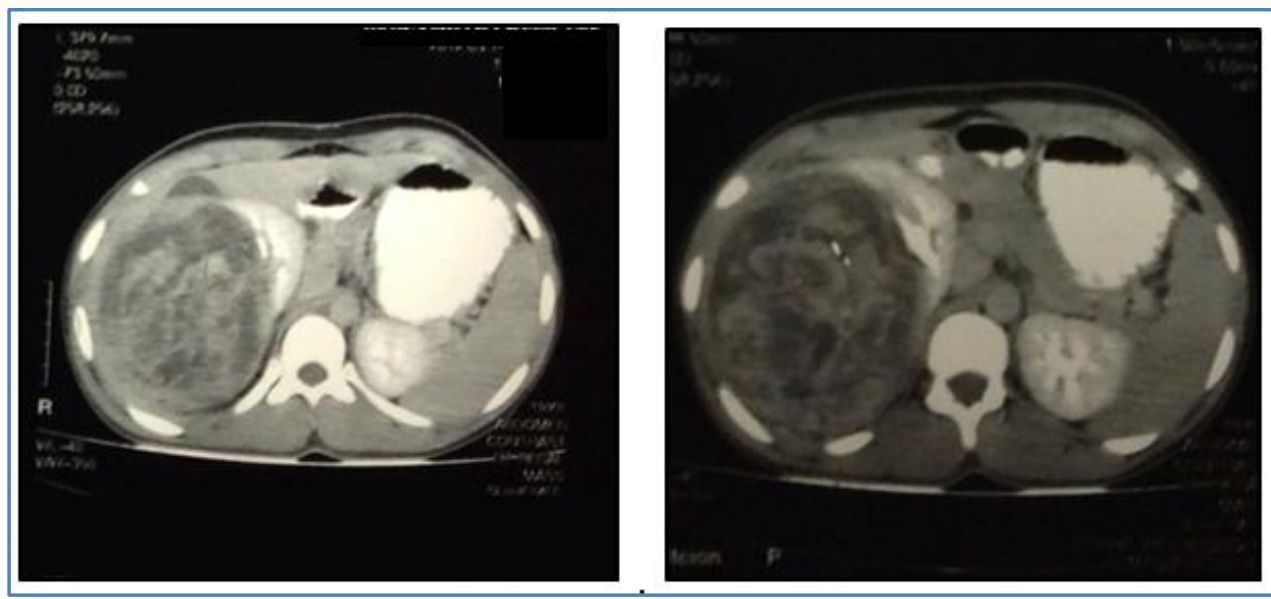

CT scan showing a large well defined heterogenous mass lesion in the right kidney

\section{AUTHORS:}

1. K. Saritha

2. T. Shravya

3. K. V. Sireesha

\section{PARTICULARS OF CONTRIBUTORS:}

1. Associate Professor, Department of Obstetrics \& Gynaecology, Siddhartha Medical College, Vijayawada, A. P.

2. Post Graduate, Department of Obstetrics \& Gynaecology, Siddhartha Medical College, Vijayawada, A. P.

\section{FINANCIAL OR OTHER} COMPETING INTERESTS: None
3. Post Graduate, Department of Obstetrics \& Gynaecology, Siddhartha Medical College, Vijayawada, A. P.

\section{NAME ADDRESS EMAIL ID OF THE}

\section{CORRESPONDING AUTHOR:}

Dr. K. Saritha,

Plot No. 15, Indian Airlines Colony,

Opp. Football Grounds, Trimulgherry,

Secunderabad-500015.

E-mail: saritha.kottu@gmail.com

Date of Submission: 03/02/2015.

Date of Peer Review: 04/02/2015.

Date of Acceptance: 13/02/2015.

Date of Publishing: 23/02/2015. 